\title{
Current Practices in Final Year Engineering Design Courses
}

\author{
Colin Vincent \\ Department of Mechanical Engineering \\ University of Victoria \\ cvincent@uvic.ca
}

\author{
Peter Wild \\ Department of Mechanical Engineering \\ University of Victoria \\ pwild@uvic.ca
}

\begin{abstract}
In order to gain understanding of the current practices in capstone design courses, a comprehensive literature review of Canadian electrical, mechanical, and computer engineering capstone courses was undertaken. To classify this information, primary elements of a capstone design course, such as project scope and project sourcing, were defined. The results of the review are presented and compared with US capstone data. The major themes are identified and the results provide insight into the state of the art of North American capstone education.
\end{abstract}

\section{Introduction}

The final year engineering design project course has become commonplace in engineering programs across North America. Accreditation in Canada and the United States specifies that the engineering curriculum must culminate in a significant design experience $[1,2]$. This requirement has been met in most accredited programs through the implementation of final year project courses, commonly referred to as capstone design courses [3].

The objective of this report is to document current practices in final year project courses in the Canada and the United States, with an emphasis on Canadian mechanical, electrical, and computer engineering programs. Based on information available on course and instructor websites, and in the engineering education literature, capstone courses at 25 Canadian engineering schools have been reviewed. Where relevant, results from several US capstone surveys are also included.

\section{Primary Elements of a Capstone}

Capstone design courses can be categorized according to their primary elements. These primary elements are scope, degree of freedom, source, allocation, deliverables, teamwork, and instruction. Additional secondary elements are also identified to further describe capstone courses. The elements are described in the following sections.

\subsection{Scope}

The scope of a design project is the breadth of the design process that it encompasses. The design process is a fluid and iterative process. It can be defined as consisting of the following stages:

- Needs Analysis

- Problem Identification / Specification Development

- State-of-the-art Review

- Generation of Alternative Conceptual Designs

- Assessment of Alternative Conceptual Designs

- Selection of a Preferred Conceptual Design

- Detailed Engineering

- Implementation

The scope of capstone design projects can consist of all or a subset of these stages. A project of reduced scope is one that omits one or more of the design process stages. For example, a design to specification project omits the first stage, needs analysis, and substantially or completely omits the second stage, problem identification / specification development.

Two examples of courses that encompass the complete design process are the mechanical capstone at UBC [4] and the electrical and computer engineering capstone at the University of Toronto [5].

As can be seen from Figure 1, completion of the full design process is uncommon in Canadian capstone design courses. $91 \%$ of courses reviewed were considered to be of reduced scope. The fundamental needs analysis stage is the most commonly omitted stage ( $69 \%$ of courses). It is usually omitted in favour of immediate problem identification, wherein a team 
develops specifications from given requirements. The state-of-the-art review (SOA) usually takes the form of an academic and commercial literature search and is omitted in $31 \%$ of the courses reviewed. Implementation is absent in $41 \%$ of courses. $32 \%$ of courses omit one or more other design process stages.

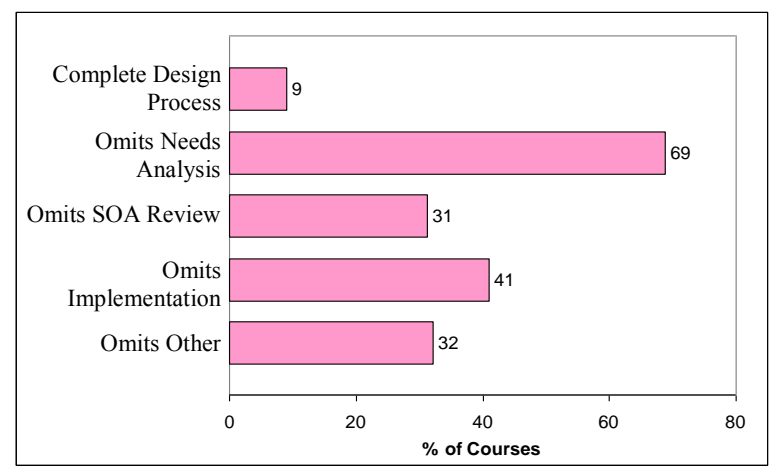

Figure 1. Scope of Canadian Capstone Projects

\section{Example: University of Toronto}

The University of Toronto offers a two-semester electrical and computer engineering capstone. The project scope encompasses the complete design process. Student teams are expected to question and negotiate the requirements given to them by the client and in doing so, to iterate between needs analysis, problem identification, and state-of-the-art review. Students brainstorm to generate alternative concepts, assess the concepts, and select one with which to proceed to detailed engineering and implementation.

\subsection{Degree of Freedom}

Degree of freedom (DOF) represents how much freedom student teams have to arrive at a solution. This differs fundamentally from the scope element, in that the DOF element indicates the constraints placed upon the range of acceptable solutions, and not the omission or inclusion of stages in the design process. Projects can range from completely open-ended to rigidly constrained.

None of the reviewed project courses is truly openended. All face, at minimum, institutional constraints on time and deliverables that indirectly limit DOF. Thus, the use of the term open-ended refers to a project where the full range of possible solutions is admitted. A project course is considered to be openended if students have opportunity to pursue openended projects.

An example of a constrained course would be the first course in the mechanical capstone sequence at Memorial [6], while the electrical capstone at UWO runs open-ended projects [7].
The vast majority of Canadian courses reviewed are considered open-ended (96\%). Only a few courses were found to be highly constrained.

\section{Example: Memorial University of Newfoundland}

The Memorial University of Newfoundland (MUN) offers a sequential two-course, two semester, mechanical capstone in the final year of study. In the first course, the instructor supplies students with a single project. In the spring of 2006, teams of 3 to 5 students designed and prototyped a human powered potable water distillation units to compete in an internal, end-of-semester contest [6]. This project was sourced from an ASME competition [8].

The project was of reduced scope since students did not analyse fundamental needs. In the problem identification design stage, a significant portion of the technical form of the solution was pre-determined by the competition rules. Thus, this project leaned towards the constrained end of the DOF continuum.

\subsection{Source}

The source element identifies the source of the project needs or problem. Project sources include industry and non-profit organisations, faculty research, instructors, students, and external competitions.

The most common project source in Canadian final year project courses is faculty research, which is found in $67 \%$ of capstone courses (Figure 2). This is particularly the case in electrical and computer engineering, where $77 \%$ of courses use faculty project sourcing. However, faculty tend not to be the only project source used. Only $4 \%$ of Canadian capstone courses use faculty as the sole project source.

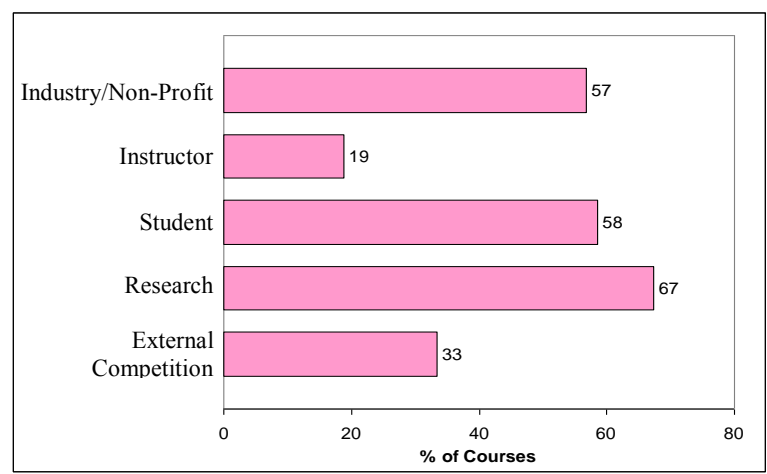

Figure 2. Source of Canadian Capstone Projects

In courses with faculty supervisors, faculty projects are convenient because the faculty supervisor/ advisor/mentor is also the client. In faculty-sourced projects, a significant number, if not all, of the department faculty are involved. 
Student project sourcing, found in 58\% of Canadian courses, is the second most common approach. Student sourcing is particularly prevalent in electrical and computer engineering courses where $73 \%$ of courses use this source. In mechanical engineering, it is employed in only $44 \%$ of courses, which places it behind industry, faculty, and external competitions as a source.

$57 \%$ of Canadian final year projects use industry or other private or public external sources. This figure is highest in the mechanical programs where industry is the most common project source (65\%).

Different approaches are taken to solicit and manage industry sources. Some institutions directly solicit companies $[4,9,10]$, while others have students recruit industry sponsors [11]. Companies are usually required to provide a mentor or contact for the student team. Some universities charge fees as high as thousands of dollars for student work on the project and use of the university facilities [5, 12]. Others charge nothing, or request 'in-kind' support for the student team's budget $[4,10]$. Often, companies are also required to provide their own facilities for student prototyping or to fabricate a prototype in-house.

With industrial clients, concerns arise over intellectual property (IP) ownership and confidentiality. These issues are usually determined through IP agreements between the three stakeholders: the students, the client, and the university. For example, the University of Alberta's mechanical capstone has two standard agreements. One allots IP ownership to the student, and the other allots it to the client. The client chooses which agreement to enter. In both cases, the university reserves the right to use the project material for academic purposes [9].

External competitions, as a project source, are used by $33 \%$ of capstone courses in Canada. This source is vastly more popular in Canadian mechanical engineering courses (58\%) than in electrical and computer engineering courses (8\%).

Instructor-sourced projects are the least common. They are present in $19 \%$ of the Canadian capstone courses reviewed.

In the US, industry sourcing has increased from 59\% in 1994 to $71 \%$ in 2005 (Figure 3). The faculty research project source was found in $46 \%$ of capstone courses and external competitions were the source of projects in $24 \%$ of courses. $15 \%$ of courses had student-sourced projects. The "Book" source category represents courses that sourced projects from books and is not directly comparable to any of the Canadian source categories in Figure 2.

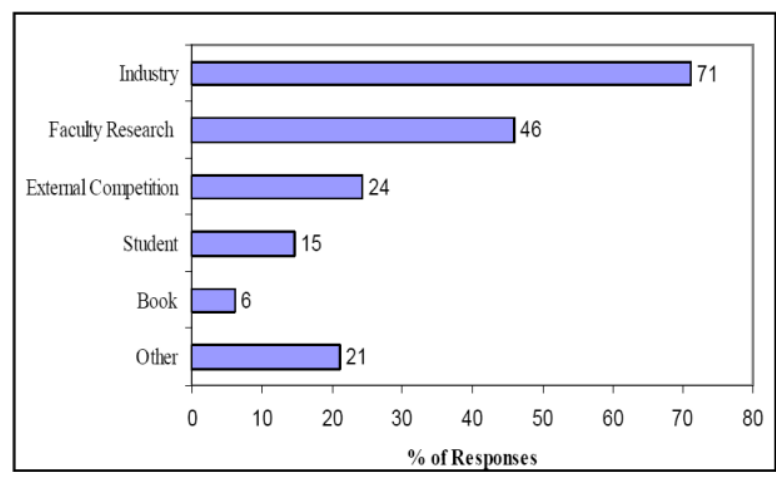

Figure 3. Source of US Capstone Projects [3]

\section{Example: University of Western Ontario}

The University of Western Ontario (UWO) offers two final year mechanical engineering design project courses. The two courses differ only in the type of project sourcing used [12]. One course sources its projects from industry and external competitions that have industrial sponsorship. The other course has student, research, and external competition project sources. External competition projects are encouraged. UWO has well developed student teams that participate in a number of competitions, such as Formula SAE, solar car challenges, SAE Mini-Baja, SAE Aero, and various robotics contests. Available competition projects are posted on the course website. Students may sign up for these, or propose their own. Project teams of three students are also encouraged to form new competition teams and engage in external competitions without prior established UWO presence. Such competitions include SAE Formula Hybrid, the Pegasus Aircraft Group project, and the Elevator 2010 competition [12].

\subsection{Allocation}

The allocation element defines how the project or projects are distributed amongst student teams. Project allocation may be single, multiple-unique, or multipleunified. In single allocation, numerous teams work independently on a single project, often in a competitive manner. In multiple-unique allocation, teams work on distinct and independent projects. Multiple-unified allocation breaks down a large project into smaller interdependent, or semiindependent, sub-projects. Each group then works on a sub-project.

The allocation types are not mutually exclusive. It is possible for a course to offer any combination of allocation options. For example, Concordia's mechanical capstone mixes all allocation schemes [13].

The multiple-unique allocation scheme is by far the most common Canadian allocation type. It is used in 
$96 \%$ of Canadian capstone courses (Figure 4). This figure falls to $76 \%$ for pure multiple-unique, i.e. where multiple-unique is the only allocation used (one team per project). Multiple-unique is often combined with the multiple-unified or single allocation project types and this reduces the number of different projects that the institution must maintain.

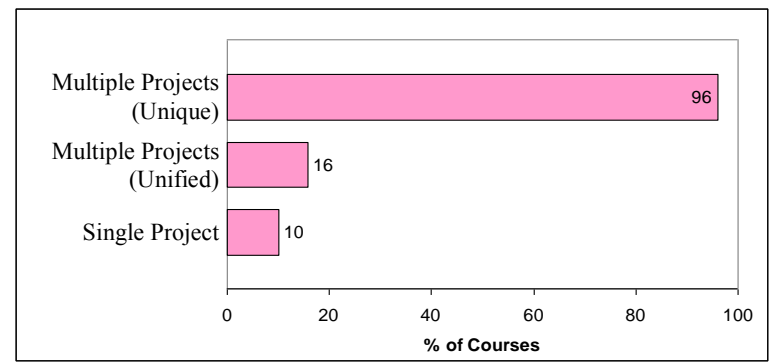

Figure 4. Allocation in Canadian Capstone Courses

The dominant approach to managing multiple-unique projects is to have faculty advisors or supervisors associated with projects in their area of expertise. Their relationship with their student team(s) ranges from mentor to evaluator. Depending on the project source, they may also act as the client in researchbased projects or as a liaison in industry-sponsored projects. In addition to the advisors/supervisors, these courses usually have faculty course coordinators that handle administrative and project vetting issues.

Multiple-unified allocation is used in 16\% of Canadian courses. It is more common in mechanical engineering capstones $(23 \%)$ than in electrical and computer engineering capstones ( $8 \%$ ).

The single allocation scheme occurs in 10\% Canadian capstone design courses. An advantage of single project allocation is that designs are easier to evaluate against common performance criteria. This evaluation may take the form of a competition. Single allocation is potentially the least resource intensive of project allocation types since it is not required to maintain a large portfolio of separate projects or the associated intellectual and physical resources.

Pure multiple-unique allocation was found in $71 \%$ of American capstone courses (See "1" in Figure 5). Pure single allocation is rare in US capstones (see "All" in Figure 5). Figure 5 does not give any comparable data for the use of the multiple-unified allocation scheme. It does, however, indicate that single and multiple allocation types are often combined.

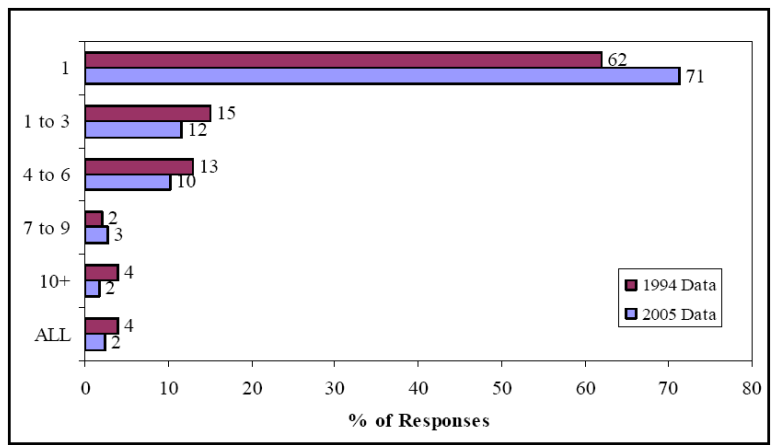

Figure 5. Number of Teams per Project in US Capstones [3]

\section{Example: Carleton University}

Carleton's Mechanical and Aerospace Engineering Department two-semester capstone is a hybrid multiple-unique/unified course. This means that a number of unique projects are each broken down into interdependent sub-projects.

There are six independent on-going multi-disciplinary projects (multiple-unique), each with its own faculty project manager for coordination. The projects are as follows: an unmanned air vehicle system, a microsatellite, the Formula SAE entry, a zero-emission gas turbine, the Carleton University Simulator Project (a vehicle simulation facility), and a medical patient simulator [14].

After students are assigned to a project team, which numbers up to thirty students, smaller teams are formed to tackle the different aspects of the project (multiple-unified). Student teams must interact within their immediate team, as well as coordinate their efforts with the larger project team. Each project team also has from three to seven lead engineers from faculty or industry, as well as graduate student involvement. One or two faculty lead engineers directly supervise each student team [15]. The course has a low student to faculty ratio and is "heavily resource intensive" [16].

\subsection{Deliverables}

This element describes the course deliverables. Typical deliverables are reports, prototypes, presentations, poster exhibitions, or some combination thereof.

Presentations and reports were universally required deliverables among Canadian courses.

Embodiment projects, those in which a working prototype is fabricated, give students the broadest design experience, as the implementation design stage is incorporated. Implementation is necessary to perform testing and verification of the design. $59 \%$ of Canadian capstone courses reviewed have a completed 
or working prototype deliverable requirement (Figure $6)$.

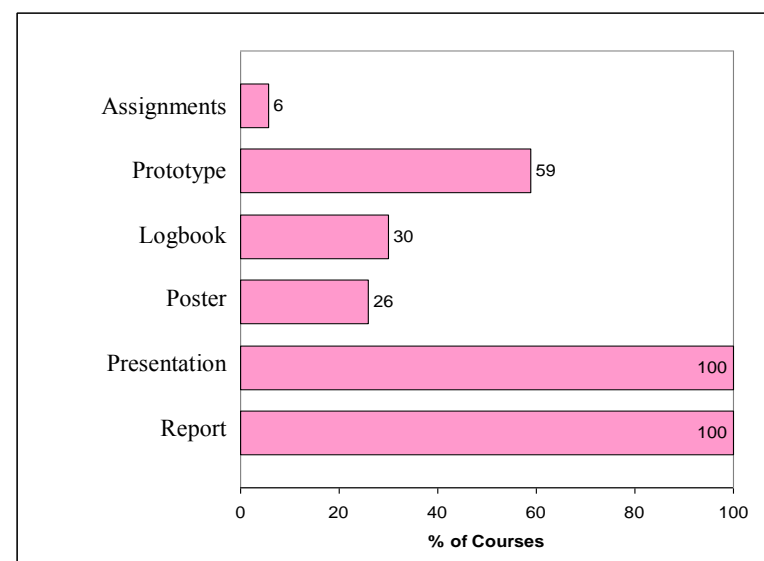

Figure 6. Deliverables in Canadian Capstone Courses

Projects with prototype deliverables are also the most time consuming and resource intensive. Canadian capstones that have a prototype deliverable tend to have multiple semester durations. $90 \%$ of Canadian capstone sequences that have a prototype deliverable are two semesters or greater in duration.

Design logbooks are required in only $30 \%$ of Canadian capstones. However, logbooks are encouraged as good practice in some courses that do require them as a deliverable such as Toronto's ECE capstone [5].

Posters are a deliverable in $26 \%$ of Canadian courses. They are usually supportive of a presentation or design exhibition. Assignments ancillary to the project, such as problem sets and labs, are uncommon (6\%).

The data presented in Figure 7 indicate that presentations are nearly universal in US capstones. See Table 1 in Section 3.4 for frequency of deliverables in US courses in the context of evaluation.

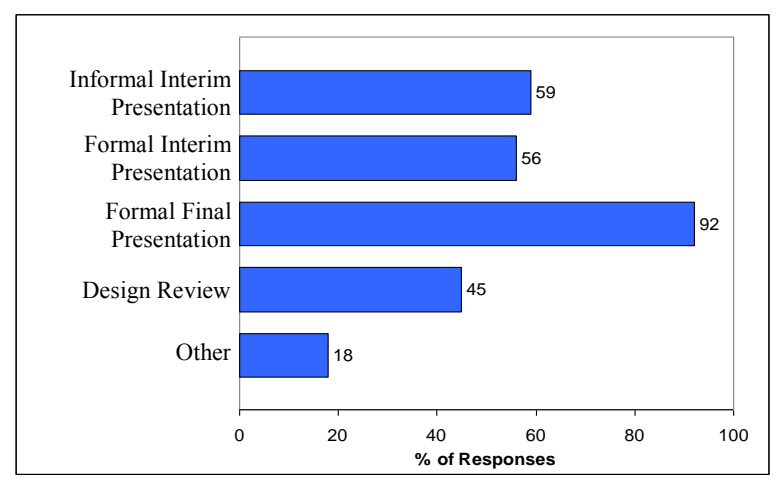

Figure 7. How Students Present Their Work in US Capstones [17]

\section{Example: University of Waterloo}

Waterloo offers a mandatory three-course electrical and computer engineering capstone sequence. Students receive design and supportive instruction, form teams of 4 to 5, and engage in needs analysis and specification development in the second semester of their third year. Specific deliverables for this first course are a project agreement, abstract, project specification, proposal presentation, and written proposal critiques [18]. All course deliverables are pass/fail except the peer marked project presentation.

Projects are student sourced and are supervised by 'consultants.' Consultants must be university professors, lab instructors, or professional engineers. The project agreement specifies IP rights and is signed by students and the consultant [19].

The second course takes place during the first semester of the final year. Here, students engage in generation, assessment, and selection of conceptual designs; detailed design; and implementation. Deliverables include a block verification, a detailed design document (descriptions, schematics, bills of materials), a prototype test checklist, a prototype demonstration, and an experience report. The block verification report is an analysis of the system conceptual block diagram and is meant to verify the suitability of the system components. The experience report explains any deviations from the project plan or the design requirements. It estimates the amount of work that would be required to move the prototype design to real production and also lists possible improvements that could be addressed in a redesign [18]. All deliverables for this course are pass/fail except the prototype demonstration.

The third course runs less than a month. Student teams submit their final report, create a poster, and give a short presentation during a one-day seminar [18].

\subsection{Teamwork}

The teamwork element represents team composition and organisation. Project teams are classified by size, discipline composition, and method of formation. The team may be from a single department, several engineering departments, or even students from different faculties and degree programs. Teams can be assigned by instructors through a number of schemes or may be formed by the students.

The average number of students per team in Canadian design capstone courses is 3.3. The Canadian distribution is shown in Figure 8 and the American in Figure 9. 


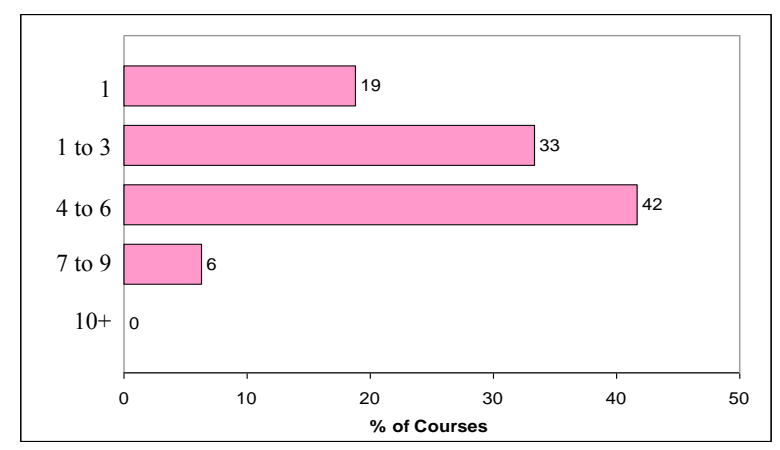

Figure 8. Number of Students per Team in Canadian Capstone Courses

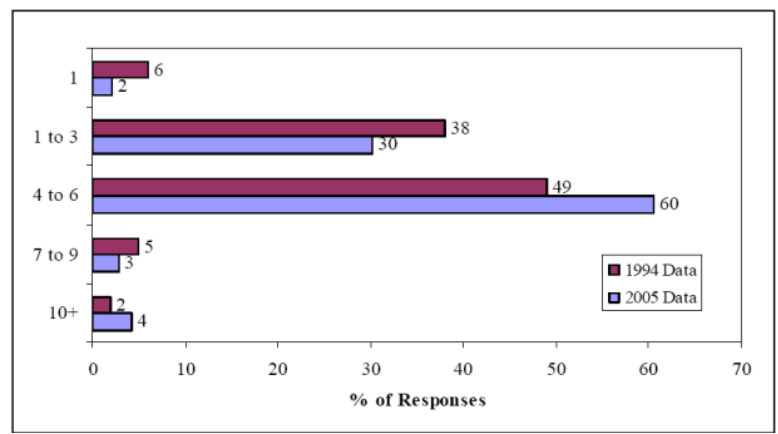

Figure 9. Number of Students per Team in US Capstones [3]

In most Canadian capstone courses, students form their own teams. However, in $13 \%$ of capstone courses, students are assigned to teams (Figure 10) via an application process $[4,13,20]$, random selection [21], or by grades [22, 23]. Interdepartmental teams are permitted or required in 39\% of Canadian capstone courses reviewed. However, it is not known how often interdepartmental teams are actually formed in courses with optional interdepartmental teams. Cross sectional project teams (teams that incorporate graduate students or undergraduate students from different years) were rare. Individual projects were required in $13 \%$ of Canadian courses.

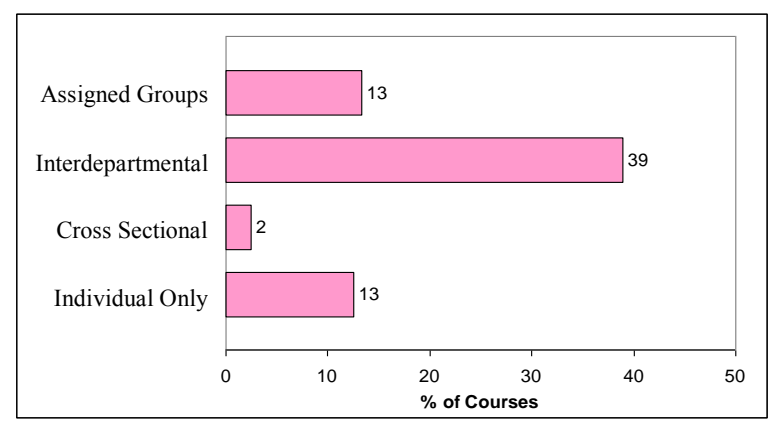

Figure 10. Teamwork in Canadian Capstone Courses
Interdepartmental teams were reported in $35 \%$ of US capstone courses (Figure 11). 18\% of US courses had individual projects. There is a sharp decrease in individual projects between the 1994 and 2005 surveys. This correlates with a similar increase in interdepartmental teams.

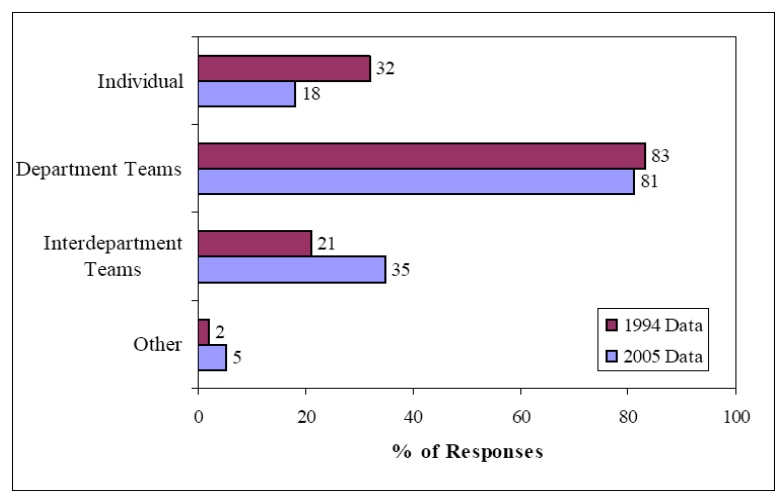

Figure 11. Teams in US Capstone Design Courses [3]

\section{Example: McGill University}

Electrical and computer engineering students at McGill University have their choice of two capstone sequences. The two sequences are identical in operation [24] and differ only in team composition and duration. The first is a single course of one semester duration. In this course, interdepartmental student teams are encouraged but not required. The other capstone sequence is two semesters in length and divided into two courses. Interdepartmental teams are required in the two-course capstone. In both courses, students form teams of two to work on student, faculty, or industry sourced projects.

\subsection{Instruction}

Instruction may take the form of a lecture series, studio discussions, guest speakers, directed lab work or any other form of directed instruction. The instruction content captured by this review is that of design (process and methodologies) and that of instruction supportive to design. Supportive instruction includes numerous topics that are complementary to engineering design projects, such as written and oral communication, project management, and engineering ethics.

$64 \%$ of Canadian final year project courses reviewed have an instructional component (Figure 12) and 44\% provide design specific instruction. Figure 12 also shows the frequency of supportive instruction in Canadian capstone courses. Project management and communication are the most common supportive topics. 


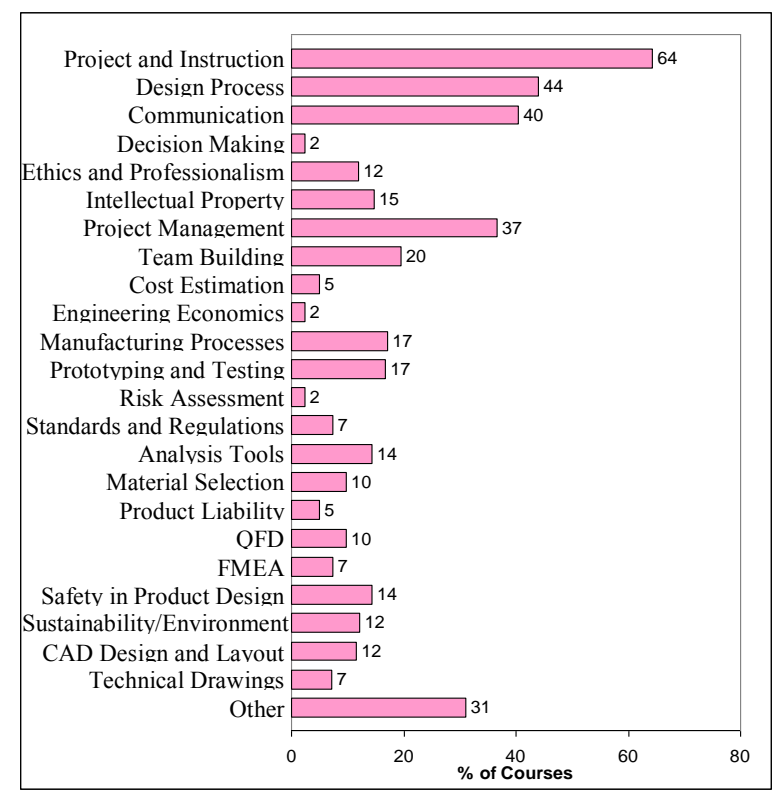

Figure 12. Instruction in Canadian Capstone Courses

On the whole, supportive design instruction is significantly more common in US capstone courses than in Canadian capstone courses (Figure 13). Of particular note is the strong emphasis on engineering ethics and oral communication. US rates of instruction increased significantly between the 1994 and 2005 surveys. Note that there is a substantial, but not complete, overlap in topic categories between Canadian and US data in Figures 12 and 13.

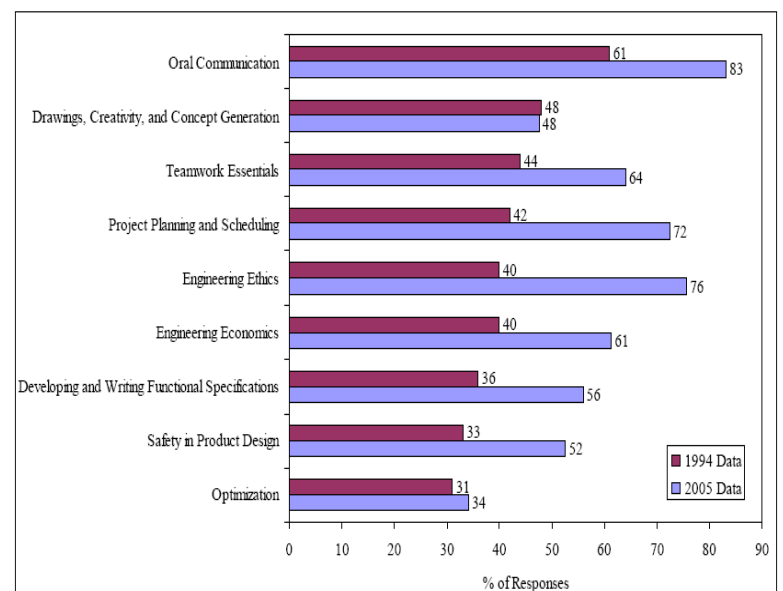

Figure 13. Subjects Taught in US Capstones (Most Frequently for 1994 Survey) [3]

\section{Example: University of Alberta}

The University of Alberta offers a one-semester mechanical capstone course. Instruction is provided by the two course instructors and by guest speakers during a semester long lecture series. Design instruction is given in instalments so that it paces the progress of the project. Design process instruction covers the following: problem definition and specification development; conceptual design; and detailed design. Supportive topics include: project scheduling, intellectual property, manufacturing, cost estimation, posters, and presentations [9].

\section{Secondary Elements of a Capstone}

A number of secondary course elements were also reviewed at Canadian universities. These elements are the Formalisation of the Design Process, Duration and Workload, Resources, and Evaluation Methods. These secondary elements are semi-dependent extensions of the primary elements. When considered in addition to the primary elements, a relatively complete description of a course is obtained.

\subsection{Formalisation of the Design Process}

Formalisation of the process denotes whether students are expected to adhere to a well-defined design process as they proceed with their projects. This process may have been learned in a prior course, taught in the project course, explained in a text book, or any combination thereof. An example would be the Conceive, Design, Implement, Operate (CDIO) process employed at Queen's University [25].

Student teams are expected to adhere to a formalised design process in $66 \%$ of Canadian capstones reviewed. This number was slightly higher in mechanical capstones (73\%) than in electrical and computer engineering capstones (58\%).

\subsection{Duration and Workload}

Duration and Workload describes the duration of the capstone sequence, the estimated individual student weekly workload.

The average calendar length of Canadian final year project was 1.8 four-month semesters. It is more useful to speak about the length of the project than the length of a course since many capstone projects continue across two or more sequential courses, which are essentially one course. There were only two projects that exceeded two semesters. The majority $(73 \%)$ of projects lasted two semesters (Figure 14). 


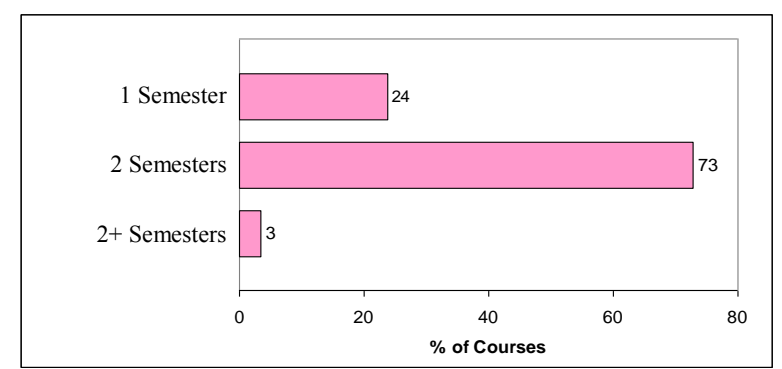

Figure 14. Duration of Canadian Capstone Sequences

The variety in course duration is greater in the American capstones. US capstones are typically of shorter duration than their Canadian counterparts (Figure 15).

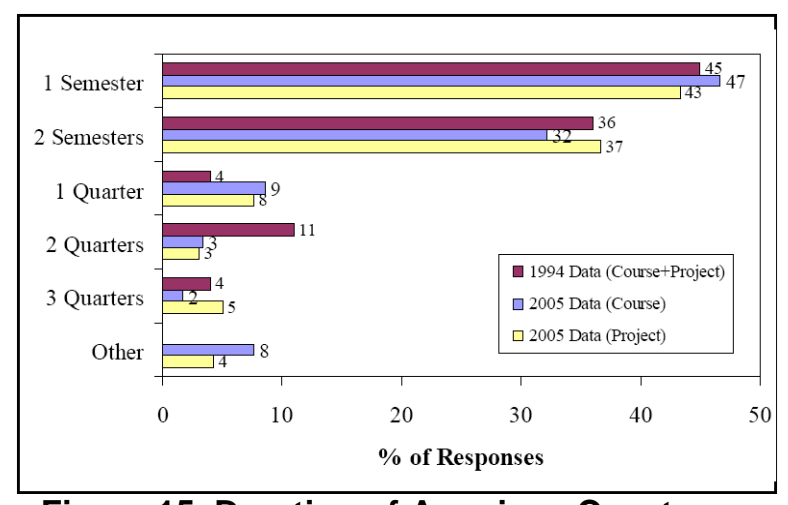

Figure 15. Duration of American Capstones [3]

The estimated weekly workload is the average time per week that the course designers or instructors expect that students must spend on the project course. This time includes scheduled course events such as lectures and labs, as well as work done outside class hours. Weekly workload for Canadian courses ranged from 4 hours up to 20. Almost all weekly workloads were between 6 and 12 hours. The Canadian average was 9 hours.

The vast majority $(80 \%)$ of US capstone courses had between 4 to 12 hours of expected workload per week outside of class time [3].

\subsection{Resources}

The average number of participating faculty per Canadian capstone course is 16 . The average ratio of students to faculty stands at approximately $7: 1$. This ratio ranged from essentially one to one to upwards of $90: 1$. Student to faculty ratio data is given for US capstone courses in Figure 16. However, the average ratio is not known, but can be estimated to be slightly higher than the Canadian figure.

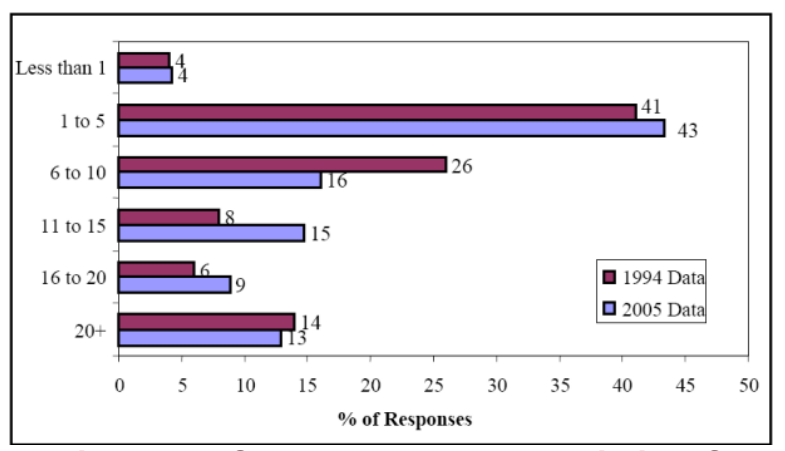

Figure 16. Student to Faculty Ratio in US Capstone Courses [3]

The average number of teaching assistants per Canadian course was 2.4. Unfortunately, these figures for faculty and TAs do not incorporate the level of time commitment of the individuals to the course.

In Canadian capstones, CAD tools and fabrication facilities were made available to students in $96 \%$ and $89 \%$ of courses, respectively. Fabrication facilities were considered machine shops in mechanical programs and electronics workbenches in electrical and computer programs.

\subsection{Evaluation}

The evaluation element captures the assessment methods used in capstone design courses.

Figure 17 shows the evaluation methods used in Canadian capstone courses. The required deliverables data is also reproduced here as these deliverables were used for evaluation purposes.

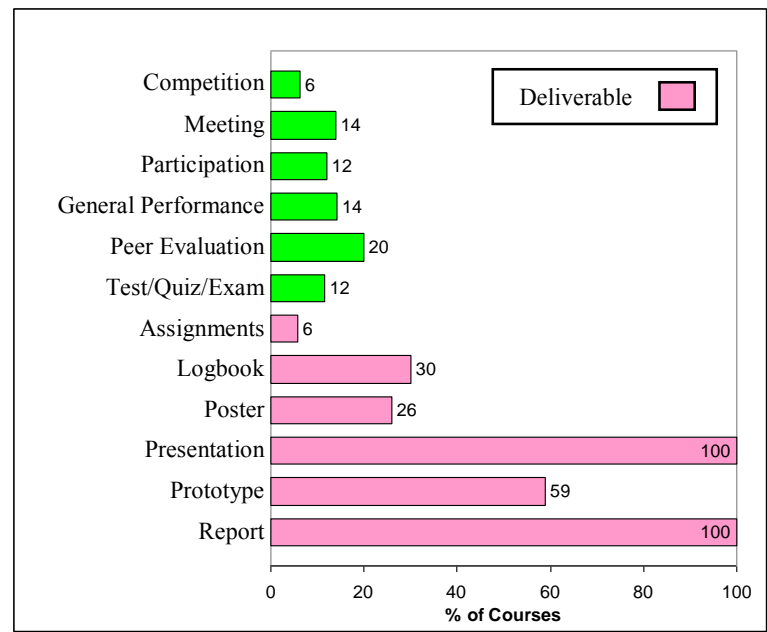

Figure 17. Evaluation Methods in Canadian Capstone Courses

Evaluation through report and presentation deliverables is universal. Peer evaluations occur in $20 \%$ of courses. Evaluation through meetings or interviews was found to be used in $14 \%$ of courses. 
Note that group and individual evaluation are not differentiated here.

Tests and quizzes are rarely used for evaluation, and are employed in only $12 \%$ of courses reviewed.

Presentations and reports were nearly universally employed in US capstone courses as of 2001 (Table 1). Peer and self assessment was popular and occurred in $68 \%$ of courses surveyed.

\section{Table 1. Assessment Methods Administered during Capstone Experience [26]}

\begin{tabular}{|l|c|}
\hline \multicolumn{1}{|c|}{ Assessment Type } & \% of Responses \\
\hline Oral Presentations & 94 \\
\hline Final Written Report & 91 \\
\hline Intermediate Written Reports & 77 \\
\hline Peer/Self-Assessments & 68 \\
\hline Portfolios & 14 \\
\hline Focus Groups/Interviews & 13 \\
\hline Other & 15 \\
\hline
\end{tabular}

\section{Conclusions}

To document current practices in capstone design courses, capstones at 25 Canadian engineering schools were reviewed. The review covered published literature and publicly available instructional material. To classify capstone courses, capstone course elements were defined. The collected Canadian data was presented with US capstone survey results. The dominant themes for the primary elements of these courses is as follows:

Scope: The majority of Canadian capstone projects (91\%) were found to be of reduced scope. This was due in large part to the omission of the needs analysis design stage (69\%) or the implementation stage (41\%). Degree of Freedom: Almost all Canadian courses $(96 \%)$ offer students projects that are significantly open-ended.

Source: Faculty research $(67 \%)$, students $(58 \%)$, and industry $(57 \%)$ are the most common source of projects in Canadian capstones. Faculty research is rarely used as the only project source. Industry sourcing is more common in US courses. $71 \%$ of US capstones reported industry sourced projects. By far the greatest sourcing difference between Canadian and US capstone courses is that of student sourcing. Only $15 \%$ of US capstones reported student sourcing.

Allocation: Multiple-unique project allocation is the dominant allocation type across North America. Despite the resources required, $76 \%$ of Canadian and $71 \%$ of US capstone courses use pure multiple-unique allocation. Multiple-unified and single allocation types are typically mixed with multiple-unique allocation.
Deliverables: Reports and presentations are the dominant deliverables in Canadian and US capstones. The majority of Canadian courses require a prototype deliverable. Of the courses with a prototype deliverable, $90 \%$ were two semesters or greater in length.

Teamwork: The average size of a Canadian capstone project team is 3.3 students and students are free to form their own teams in $87 \%$ of courses. Interdepartmental teams are found in $39 \%$ and $35 \%$ of Canadian and US capstones respectively.

Instruction: $63 \%$ of Canadian capstones have an instructional component. The most popular instructional subjects are the design process, communication, and project management. The rate of instruction in US capstones appears much higher and has increased markedly since the mid-1990s.

\section{References}

[1] Canadian Engineering Accreditation Board, "Accreditation Criteria and Procedures 2006," Canadian Council of Professional Engineers, Ottawa, Ontario, ISSN 1708-8054.

[2] Engineering Accreditation Commission, "2007-2008 Criteria for Accrediting Engineering Programs,” ABET, Baltimore, MD.

[3] S. Howe and J. Wilbarger, "2005 National Survey of Engineering Capstone Design Courses," in Proceedings of the 2006 ASEE Annual Conference and Exhibition, 2006.

[4] J. Mikkelsen et al, "Improvements to a University Capstone Design Program Through the Use of Industrial Mentors and Increased Milestone Deliverables," in Proceedings of the Second CDEN International Conference, 2005.

[5] Department of Electrical and Computer Engineering, University of Toronto. "2005-2006 ECE496Y Design Project Course website." Internet:

http://ccnet.utoronto.ca/20059/ece496yly/, 2006, [December 2006].

[6] Faculty of Engineering and Applied Science, Memorial University of Newfoundland, "ENGR 7936 Design Project Spring 2006 website.” Internet: http://www.engr.mun.ca/ adfisher/7936-06/793606\%20Index.htm, 2006, [December 2006].

[7] Department of Electrical and Computer Engineering, University of Western Ontario. "ECE 416 -

Electrical/Computer Engineering Project.” Internet: http://www.eng.uwo.ca/electrical/information/courses/ece41 6/index.html, 2006, [December 2006]. 
[8] American Society of Mechanical Engineers, "2007 ASME Student Design Challenge: Human-Powered Potable Water Still." Internet:

http://www.asme.org/Events/Contests/DesignContest/Rules Procedures.cfm, 2006, [December 2006].

[9] Department of Mechanical Engineering, University of Alberta, " Mec E 460: Senior Design Project Fall 2006 website." Internet:

http://www.mece.ualberta.ca/courses/mec465/index.html, 2006, [December 2006].

[10] Department of Mechanical and Materials Engineering, Queen's University, “Team Design Project Conceive and Design Fall 2006 - Homepage.” Internet:

http://me.queensu.ca/courses/MECH460/, 2006, [December 2006].

[11] Department of Mechanical Engineering, University of New Brunswick, "Senior Design Project." Internet: http://www.unb.ca/ME/undergrad/senior_project/srindex.ht ml, [December 2006].

[12] Department of Mechanical and Materials Engineering, University of Western Ontario, "MME 419/MME 499

Website 2006/07." Internet:

http://hyperserver.engrg.uwo.ca/mme499/, 2006, [December 2006].

[13] H. Hong et al, "Capstone Design Projects at the Department of Mechanical and Industrial Engineering at Concordia University," in Proceedings of the Second CDEN International Conference, 2005.

[14] Department of Mechanical and Aerospace Engineering, Carleton University. "Undergraduate $4^{\text {th }}$ Year Projects 2006/07." Internet:

http://www.mae.carleton.ca/maehtmls/projects.html, 2006, [December 2006].

[15] Department of Mechanical and Aerospace Engineering, Carleton University. "Project Guidelines Document Aero 4907 and Mech 4907 Issue No.3." Carleton University, Ottawa, Ontario, 2002.

[16] P. Straznicky et al, "Integrated Team Design Projects at Carleton University," in Proceedings of the First CDEN International Conference, 2004.

[17] S. Howe and J. Wilbarger, "Work in Progress: Current Practices in Engineering

Capstone Education: Further Results from a 2005

Nationwide Survey," in Proceedings of the 36th ASEE/IEEE

Frontiers in Education Conference, 2006.

[18] Department of Electrical and Computer Engineering, University of Waterloo, "Design Project Courses 2006." Internet: http://www.ece.uwaterloo.ca/ ece492a/, 2006, [December 2006].
[19] Department of Electrical and Computer Engineering, University of Waterloo, "ECE Fourth Year Design Project Agreement." Internet:

http://www.ece.uwaterloo.ca/ ece391/deliverables/pa.html, [December 2006].

[20] H. Herring and P. Gu, "Experience of Partnering with Industry to Enrich Engineering Design Education," in Proceedings of the Second CDEN International Conference, 2005.

[21] Faculty of Engineering, University of Manitoba, “025.486 - Engineering Design Course Outline.” Internet: http://www.umanitoba.ca/cgibin/faculties/engineering/courses/outline.cgi?dept no $=025 \&$ course no=486, 2006, [December 2006].

[22] Department of Electronics, Carleton University, " 4 th Year Engineering Project 2006-2007.” Internet: http://www.doe.carleton.ca/ Courses/4th_year_projects/inde x.html, 2006, [December 2006].

[23] G. Rohrauer, B. Minaker and Peter Frise, "Work in Progress: Practical 'Know-How' in Engineering: Dissection Labs and Capstone Design," in Proceedings of the 34th ASEE/IEEE Frontiers in Education Conference, 2004.

[24] Department of Electrical and Computer Engineering, McGill University, "ECSE483 Multidisciplinary Engineering Design Project I.” Internet: http://www.ece.mcgill.ca/ info483/info483.html, 2005, [December 2006].

[25] B. Surgenor, C. Mechefske, U. Wyss and J. Pelow , "Capstone Design - Experience with Industry Based Projects," in Proceedings of the First Annual CDIO Conference, 2005.

[26] L.J. MacKenzie et al, "Capstone Design Courses and Assessment: A National Study," in Proceedings of the 2004 American Society of Engineering Education Annual Conference \& Exposition, 2004. 